Article

\title{
Wet Spells and Associated Moisture Sources Anomalies across Danube River Basin
}

\author{
Danica Ciric $^{1, *}$, Raquel Nieto ${ }^{1}$, Alexandre M. Ramos ${ }^{2}$, Anita Drumond ${ }^{1}$ (iD and Luis Gimeno ${ }^{1}$ \\ 1 EPhysLab (Environmental Physics Laboratory), Facultade de Ciencias, Universidade de Vigo, \\ 32004 Ourense, Spain; rnieto@uvigo.es (R.N.); anitadru@uvigo.es (A.D.); 1.gimeno@uvigo.es (L.G.) \\ 2 Instituto Dom Luiz, Universidade de Lisboa, 1749-016 Lisboa, Portugal; amramos@fc.ul.pt \\ * Correspondence: cdanica@alumnos.uvigo.es; Tel.: +34-988-387-248
}

Received: 29 May 2017; Accepted: 15 August 2017; Published: 17 August 2017

\begin{abstract}
The Danube River Basin is the second longest catchment basin in Europe and exhibits intense climatological diversity. In recent decades, the frequency and intensity of daily precipitation extremes have suffered from an increment in many parts of the world, including Central and Eastern Europe. Wet spells are defined by the number of consecutive rainy days with different thresholds. The identification of wet spells and their trends in the rainfall time is very important for many sectors, such as agriculture, ecology, hydrology and water resources. Wet spells can lead to extreme events and cause floods and other disasters. In this study, we will attempt to characterise global precipitation in the context of wet spells and associated precipitation depth of wet spells in the Danube River Basin area using daily precipitation data, as well as analysing different approaches to identifying wet spells. The ten most intense wet spells were detected, and the most intense, which occurred on 23 September 1996, was studied in depth in terms of precipitation and associated anomalies, the synoptic situation and the anomalous transport of moisture using a Lagrangian approach. The existence of a marked west-east dipole in the field of sea level pressure between the Atlantic Ocean and the eastern Mediterranean leads to the anomalous moisture transport from the Northern Atlantic Ocean to the Mediterranean Sea, where a higher available amount of moisture existed, and subsequently penetrated within the low positioned over the Danube River Basin. In addition, an Atmospheric River was also responsible for the wet conditions in the Danube River Basin. The combination of all these factors was responsible for the extreme precipitation linked with the wet spell.
\end{abstract}

Keywords: wet spell; precipitation; moisture sources; atmospheric rivers; anomalies; danube river basin

\section{Introduction}

Extreme precipitation events in Central Europe, including the area inside of the Danube River Basin (DRB), have become very common in the last few decades and have usually been associated with related phenomena, such as flooding, landslides, storms, significant material damage and human sacrifices. One of the primary causes of extreme weather events may be a consequence of global climate changes [1]. It is known that climate change is one of the major causes of increasing temperatures, precipitation amounts and variability of precipitation events. The Danube River Basin has a very diverse climate and notably variable precipitation characteristics because of the proximity of the Atlantic Ocean, Mediterranean Sea and Alps mountain range [2]. Thus, the significant amount of precipitation in the basin area throughout the whole year may be due to the impact of these factors. When the annual precipitation scale is considered, it is clear that those months with the maximum amount of precipitation usually occur during the summer. This phenomenon is especially highlighted in the low-lying part of the Danube River Basin, where convective precipitation makes 
a significant contribution to the total amount of precipitation [3]. Conversely, the months with minimum precipitation occur in mid-winter (January and February), when the Asiatic region of high pressure disables the movement of air masses from the Atlantic to the east. The average value of annual precipitation for the Danube River Basin is estimated as $2300 \mathrm{~mm}$ in the high mountains and approximately $400 \mathrm{~mm}$ in the delta region. Precipitation values above $2000 \mathrm{~mm}$ appear in the Upper Danube Basin in the high Alpine regions and in the Central Danube Regions on the southern oriented mountain chains of the Julian Alps and Dinaric system (Figure 1), which are exposed to the influence of humid-warm air masses originating in the Mediterranean [2,4].

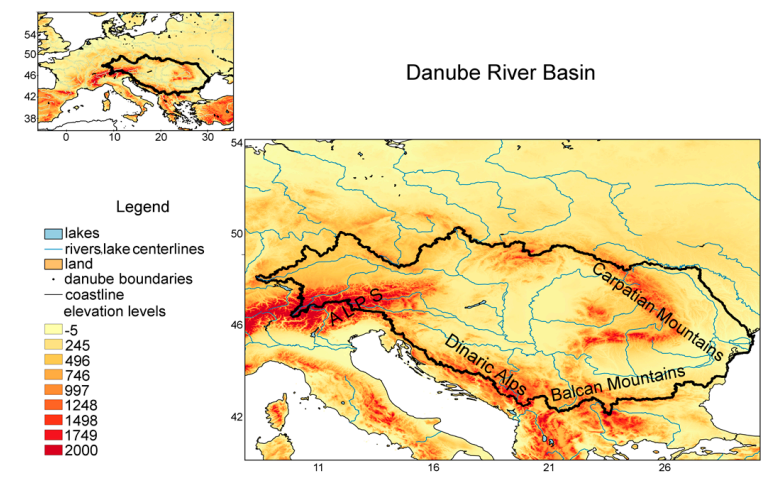

Figure 1. Black line indicates the boundaries of the Danube River Basin. Colours represent elevation levels in metres.

To understand the mechanism of increase in mean and extreme precipitation, it is important to analyse wet spell events on different time scales and their associated precipitation magnitude [5]. Europe is similar to global trends, in that increases in average and extreme rainfall and their variability are expected for areas in the middle northern portion, signifying an increasing risk of flooding; alternatively, in southern regions, less precipitation and frequent dry spell periods may lead to increasing drought trends [1].

The primary and most common reason for river flooding in Central Europe, including the area of the Danube River Basin, is heavy precipitation events, with the exception being snow melting during the winter period. It is important to stress that those heavy rain events of different duration (in the range of one to several days) usually result in a large amount of precipitation per square metre. The most significant conditions are certainly intensity, magnitude and spatial-temporal distribution of precipitation, but also, significant roles have specific conditions within the river basin at the moment of heavy precipitation [6]. In recent years, the largest floods in the area of the Danube River Basin occurred in 2002, 2006, 2013 and 2014. As a consequence, all of the associated areas experienced economic losses in the range of billions of euros and, what is much worse, suffered human causalities [7]. Many authors have studied these flood events, their causes and impacts [8,9]. Generally, two main reasons are cited as leading to the extreme flood events. The floods which occurred in 2002 and 2006 were induced by a huge amount of precipitation falling over a short time period, which produced a massive single flood event in the territory of the Danube River Basin. In contrast, the 2010 flood occurred as a consequence of a high number of rainfall events during the whole year, which caused a large number of flood events throughout the area of the Danube, economic losses around two billion euros, and 35 causalities [7].

As previously indicated, when extreme precipitation events are analysed, two terms (or factors) should be taken into consideration: (i) if the event occurs during a short period (hours or less than one day in extreme situations) which happens as a result of a strong convergence of atmospheric water vapour with local dynamic processes, or (ii) if it occurs during a prolonged time period, when the extreme precipitation is related to huge amounts of precipitation occurring over several weeks, months or seasons; in this last case, the duration of rainfall is the primary reason for the accumulation of large amounts of precipitation, which impacts nature and society through flood events [10]. 
There is no precise and generally accepted method for the calculation and identification of extreme precipitation events. Some authors [11,12] have used the highest recorded precipitation amount at some rain gauge stations as the selection criteria, whereas others have utilised the socioeconomic impacts of extreme precipitation events as their criterion [13]. Typically, all methodologies for ranking and identifying extreme precipitation events at least require daily precipitation values [1]. However, ranking and analysing extreme precipitation events (wet spell events) does not depend solely on available daily precipitation data, but additionally requires dataset resolution to characterise the precipitation [14] and the chosen criteria for the methodology. There have been many studies in recent years that have given attention to extreme precipitation events in the context of wet spells and associated accumulation precipitation in wet spells events. In these studies, the authors have used different methodologies for the analysis of wet spells. One method uses IDF curves (Intensity-Duration-Frequency) for characterisation and the study of wet spells behaviour [15]. In this study, they used the term "duration" to refer to a number of consecutive rainy days in the context of one day or more, not in reference to the actual duration of rainfall events. Another approach has used precipitation anomalies to identify extreme wet or dry spells and defines wet spell events as events with a minimum of three consecutive days with precipitation anomalies more than one standard deviation (std) from daily precipitation [16].

Understanding the atmospheric moisture transport is fundamental for explaining the nature of the precipitation during extreme events [17]. The Lagrangian approach has been broadly and satisfactorily used during the last several years to compute changes in moisture along trajectories and to identify sources of moisture or sinks, all around the globe [18]. Although other approaches (such as box models and isotopes) could be used with a similar purpose, the Lagrangian model supports an important benefit: it is able to compute the track of the moisture in time and permits the identification of the main moisture sources. More information about the comparison between certain methodologies can be found in Gimeno et al. [19].

In this study, for the identification and selection of wet spell events, we used the methodology developed by Ramos et al. $[20,21]$ for the ranking of high-resolution daily precipitation extremes. The long time period analysed was from 1981 to 2015. The main objectives of this work are (i) to rank wet spell events in regards to different time scales in duration from 1 to 10 days for the whole area of the Danube River Basin using a daily precipitation dataset in high resolution and (ii) to analyse moisture source anomalies for the most intense wet spell event using a Lagrangian approach.

\section{Data and Methods}

\subsection{Precipitation Dataset}

In this work, we used the daily precipitation dataset from the Climate Hazards Group Infra-Red Precipitation with Station data (CHIRPS) project [22]. CHIRPS is a relatively new precipitation database, which has been accessible since the beginning of 2015. This database was developed by the USAID Famine Early Warning System Network with the support of scientists at the University of California Santa Barbara (Santa Barbara, CA, USA). To calculate the wet spell events with major precision, the resolution of the daily precipitation database used is critical, which is the main reason to choose the CHIRPS dataset instead of other available daily databases. It is considered the new environmental record for analysing and monitoring extreme events [22]. The CHIRPS database is in a $0.05^{\circ} \times 0.05^{\circ}$ degree spatial resolution in latitude and longitude from 6-hourly to 3-monthly aggregates, which makes it a unique daily database.

This database presents a combination of three types of precipitation information: global climatologies, satellite-based measurements and in situ rain gauge data. The database used for calculation wet spells events covers a temporal period from January 1981 until December 2015.

The CHIRPS dataset has been successfully used in recent publications to validate other common datasets in areas that present extreme climate or complex topography. For instance, CHIRPS has been 
used to quantify the impact of decreasing precipitation trends and increasing temperatures trends in the Greater Horn in Africa [22], and it validated using the data from 21 ground stations in Northeast Brazil [23]. CHIRPS dataset has also been used it to obtain a comprehensive evaluation of eight high spatial resolution precipitation products in an Alpine catchment, the Adige Basin in Italy [24], and to validate a hydrological model to simulate stream flow in a complex topography [25]. Additionally, the same database was successfully used for the analysis of precipitation extremes over Cyprus [26] and Bhutan [27].

\subsection{Ranking of Wet Spell Extreme Precipitation Events}

This ranking of wet spell events in the area of the Danube River Basin is based on the method developed by Ramos et al. [20,21], which used daily-normalised precipitation anomalies for the ranking of multi-day extreme precipitation events according to the accumulated amount of precipitation and the spatial distribution in the Iberian Peninsula.

The ranking is based on the magnitude of an event $(\mathrm{R})$, which is obtained after considering the area affected as well as its intensity in every grid point, and taking into account the daily-normalised departure from climatology. This method [20] for the Iberian Peninsula was partially adapted from another approach [28], that has suggested some criteria to classify each day in terms of extremeness using different meteorological variables. The use of normalised precipitation departures from the seasonal climatology allows us to measure the rarity of an event given by the standardised precipitation anomalies. With this standardisation, we are assured of the different statistical distribution of daily areal precipitation among different areas that are being studied. Therefore, it $[20,21]$ can be applied easily to other regions of the world using different gridded precipitation datasets (model data or observations), and the use of different time scales [21] is directly applicable to assess persistent precipitation episodes over a certain region.

To obtain a final $R$ index to calculate the wet spell events in different durations, several steps should be applied prior to the final ranking (as in $[20,21]$ ). In the first step, we calculated daily normalised precipitation anomalies $(N)$ for each grid point as the difference between the precipitation values for the day under analysis and the daily mean climatological value and later divided by the daily standard deviation climatological value. With this we ensure the different statistical distribution of daily areal precipitation among different areas of the Danube basin are taken into account and can easily be compared. The use of standardised precipitation anomalies to evaluate heavy large-scale rainfall events was already used with success by other authors in central Europe [6]. Therefore, we are confident that this methodology [21] reflects wet spell events in the Danube River Basin particularly well.

Furthermore, for this computation, only grid points with precipitation amounts above $1 \mathrm{~mm}$ were considered. The reference period that we took into account is the complete period of the CHIRPS precipitation data from 1981 until 2015. The noise in both time series has been smoothed by applying a 7-day running mean to the climatological series. Thus, climatological normalised precipitation anomalies are computed, taking into account each day and each grid point. The final daily index, according to which wet spell events were ranked, was:

$$
R=A \times M
$$

where $A$ denotes the area in percentage which has precipitation anomalies above two standard deviations, and $M$ is the mean value of these precipitation anomalies over $A$.

In a second step, we have also computed the accumulated precipitation anomalies for a certain period (NCC): that is, $N$ added during different time periods. NCC represents in our case the wet spell events on different time scales. Finally, in the last step, we performed the ranking of wet spell events according to the final index $R$, which computed the magnitude of precipitation for each wet spell event in different durations. The main idea is to sum the daily normalised anomalies (see previous paragraph) over different time scales ( 2 to 10 days) to allow ranking the different anomalous precipitation on multi-day periods. For each time scale's (2 to 10) accumulated precipitation standardised anomalies, 
the magnitude of the wet spell event is $R$ obtained after multiplying: (1) the area $(A)$, expressed as the percentage that has accumulated precipitation anomalies (computed over different time scales) higher than two standard deviations and (2) the mean value of these accumulated precipitation anomalies $(M)$, considering only grid points with precipitation anomalies of more than two standard deviations.

Wet spell events on the time scales from 1 day until a maximum of 10 days have been calculated, but for the sake of simplicity only 1,3, 5, 7, and 10 days of length are presented in this study (time periods between 7 and 10 days are the typically synoptic time scale). These different multi-day extreme rankings will show that specific extreme events at shorter time scales (e.g., 2-3 days) may be absent from the top ranks at longer time scales lists (e.g., 10 days) and others that appear at long time scales are not present at shorter time scales.

Furthermore, we should make clear that the ranking of wet spell events illustrated in this paper is not related to economic impacts and/or human impacts, such as causalities, injuries or homelessness. The rankings of wet spell events are constituted by the daily high precipitation amount and the associated spatial extension.

\subsection{Moisture Sources Anomalies}

The second part of this work is to compute precipitation anomalies of moisture sources for the identified wet spell events in different time scales. The moisture source anomalies are computed using the Lagrangian FLEXPART V9.0 model. To track the changes in atmospheric moisture along trajectories the approach uses ERA-Interim reanalysis data from ECMWF (European Centre for Medium-Range Weather Forecast), which are accessible at approximately $80 \mathrm{~km}$ (T255 spectral) on 60 vertical levels from the surface up to $0.1 \mathrm{hPa}$, available at each 6-hour time interval [29]. The model developed by Stohl and James $[30,31]$ consists of dividing the global atmosphere into approximately 2 million particles (air masses), which are transported by the three dimensional wind field along their trajectories. Transport time of the trajectories were limited to 10 days, as this is the mean water vapour lifetime in the atmosphere [32]. Changes in specific humidity (q) and locations of air particles were recorded every $6 \mathrm{~h}$. The increases (e) and decreases (p) in moisture along each trajectory may be expressed by changes in specific humidity $(\mathrm{q})$ by the equation:

$$
\mathrm{e}-\mathrm{p}=\mathrm{m} \mathrm{dq} / \mathrm{dt}
$$

where $m$ is the mass of the particle. By adding $(e-p)$ values of all air particles residing at each time step over a specific area (in this case, over an area of $1.0 \times 1.0$ degrees in latitude and longitude), it is possible to obtain the instantaneous values of the $(E-P)$ balance, where $(E)$ denotes evaporation and $(\mathrm{P})$ the precipitation rate per unit area.

According to Stohl and James [30,31], this approach has two main disadvantages: (1) it is not possible to make separate calculations of $E$ and $P$, and (2) the results are highly dependent on the input data quality. In addition, the fluctuations in $\mathrm{q}$ along individual trajectories may also occur for numerical reasons (e.g., because of the interpolation of q). However, such numerical noise may be partly mitigated by the large numbers of particles contained in an atmospheric column. A more detailed description of the use of this Lagrangian approach and backward/forward analysis for tracking moisture can be found in many research studies which have used this method for tracking variation and/or identification of moisture sources in many different worldwide regions, such as the Mediterranean region [33], Central America [34], Iberian Peninsula [35], Iceland [36], Greenland [37], China [38], and Niger River basin [39].

To calculate the anomalies for the wet spells detected, the first step is to compute the 35-years climatology (1981-2015) for the moisture sources over the Danube River Basin for those specific days of interest (daily climatological value). Precipitation anomalies of moisture sources were calculated as the difference between the $\mathrm{E}-\mathrm{P}>0$ value (backward analysis) for the day/days of the wet spell events and the daily climatological value. 


\section{Results}

\subsection{Detection of the Wet Spells}

Table 1 presents the top ten extreme wet spells for the area of interest, the Danube River basin, for five accumulated periods of the lengths of 1,3, 5, 7 and 10 days. The date that appears for each wet spell indicates the final day of each event. For instance, the wet spell event with a length of 3 days on 24 September 1996 (top 1) signifies that this event includes accumulated precipitation anomalies for that day (24 September 1996) and the two previous days: 23 and 22 September 1996, that is, 3 days in total. The same is true for longer periods.

Table 1. The top ten wet spell events in the Danube River Basin (DRB) according to the different length of the events (1, 3, 5, 7, and 10 days). Column denoted with A corresponds to area of the DRB in percentages that had precipitation anomalies above 2 std (standard deviation). Column $\mathbf{M}$ corresponds to mean magnitude of precipitation anomalies of $A$, and the last column denoted with $\mathbf{R}$ represents the final index of ranking of wet spell events. The final column (R) is the magnitude of the events. In bold are represented wet spell events in different durations that we took into consideration and all events include the most anomalous one for the 1-day ranking identified event with an initial day on 23 September 1996.

\begin{tabular}{|c|c|c|c|c|}
\hline & & $A(\%)=$ Area & M = Mean Magnitude & $R=$ index of Ranking \\
\hline (a) & \multicolumn{4}{|c|}{1 day duration-Wet Spell Events } \\
\hline 1 & 23 September 1996 & 44.87 & 4.43 & 198.65 \\
\hline 2 & 28 December 2014 & 50.92 & 3.32 & 168.81 \\
\hline 3 & 6 November 1985 & 40.26 & 3.89 & 156.70 \\
\hline 4 & 1 March 2008 & 40.48 & 3.84 & 155.58 \\
\hline 5 & 18 February 1994 & 44.66 & 3.19 & 142.60 \\
\hline 6 & 27 November 1983 & 40.79 & 3.44 & 140.42 \\
\hline 7 & 6 May 1987 & 36.20 & 3.81 & 138.02 \\
\hline 8 & 14 March 2013 & 43.32 & 3.18 & 137.91 \\
\hline 9 & 2 March 2014 & 31.11 & 4.38 & 136.17 \\
\hline 10 & 27 March 1993 & 38.96 & 3.38 & 131.77 \\
\hline \multicolumn{5}{|c|}{3 day duration-Wet Spell Events } \\
\hline 1 & 24 September 1996 & 53.11 & 4.71 & 249.95 \\
\hline 2 & 23 September 1996 & 51.06 & 4.47 & 228.27 \\
\hline 3 & 25 September 1996 & 47.25 & 4.75 & 224.59 \\
\hline 4 & 11 February 1984 & 44.50 & 4.63 & 206.04 \\
\hline 5 & 6 November 1985 & 51.45 & 3.97 & 204.39 \\
\hline 6 & 8 January 2010 & 47.44 & 4.18 & 198.54 \\
\hline 7 & 6 May 1987 & 49.73 & 3.99 & 198.36 \\
\hline 8 & 10 February 1984 & 43.52 & 4.50 & 195.88 \\
\hline 9 & 29 October 1990 & 48.53 & 4.02 & 195.15 \\
\hline 10 & 31 October 1994 & 51.43 & 3.76 & 193.43 \\
\hline \multicolumn{5}{|c|}{ (c) 5 day duration-Wet Spell Events } \\
\hline 1 & 24 September 1996 & 53.66 & 4.75 & 254.85 \\
\hline 2 & 25 September 1996 & 53.45 & 4.76 & 254.22 \\
\hline 3 & 26 September 1996 & 53.67 & 4.69 & 251.71 \\
\hline 4 & 14 December 1990 & 55.32 & 4.29 & 237.58 \\
\hline 5 & 13 January 1998 & 51.67 & 4.55 & 234.92 \\
\hline 6 & 27 September 1996 & 48.54 & 4.77 & 231.42 \\
\hline 7 & 23 September 1996 & 51.73 & 4.46 & 230.92 \\
\hline 8 & 22 January 1998 & 53.15 & 4.29 & 227.95 \\
\hline 9 & 30 October 1990 & 53.80 & 4.13 & 222.08 \\
\hline 10 & 31 October 1990 & 53.84 & 4.12 & 221.67 \\
\hline
\end{tabular}


Table 1. Cont.

\begin{tabular}{lcccc}
\hline & A(\%) = Area & $\mathbf{M}=$ Mean Magnitude & $\mathbf{R}=$ index of Ranking \\
\hline (d) & 7 day duration-Wet Spell Events & & \\
\hline 1 & 1 January 1996 & 70.41 & 4.24 & 298.19 \\
2 & 15 December 1990 & 64.51 & 4.51 & 290.71 \\
3 & 2 January 1996 & 69.34 & 4.00 & 277.60 \\
4 & 14 December 1990 & 61.43 & 4.46 & 273.79 \\
5 & 7 May 1987 & 61.21 & 4.26 & 260.72 \\
$\mathbf{6}$ & 27 September 1996 & $\mathbf{5 4 . 5 9}$ & $\mathbf{4 . 7 8}$ & $\mathbf{2 6 0 . 6 9}$ \\
$\mathbf{7}$ & 24 September 1996 & $\mathbf{5 4 . 7 3}$ & $\mathbf{4 . 7 2}$ & $\mathbf{2 5 8 . 4 7}$ \\
8 & 16 December 1990 & 59.21 & 4.35 & 257.33 \\
$\mathbf{9}$ & 28 September 1996 & $\mathbf{5 4 . 3 3}$ & $\mathbf{4 . 7 3}$ & $\mathbf{2 5 6 . 9 1}$ \\
$\mathbf{1 0}$ & 25 September 1996 & $\mathbf{5 4 . 1 1}$ & $\mathbf{4 . 7 5}$ & $\mathbf{2 5 6 . 8 7}$ \\
\hline $\mathbf{( e )}$ & 10 days duration-Wet Spell Events & & 325.98 \\
\hline 1 & 23 August 2005 & 68.21 & 4.78 & 317.66 \\
$\mathbf{2}$ & 18 December 1990 & 66.39 & 4.78 & 315.91 \\
3 & 24 August 2005 & 66.78 & 4.73 & 313.98 \\
4 & 4 January 1996 & 72.31 & 4.34 & 301.29 \\
5 & 15 December 1990 & 65.40 & 4.79 & 300.85 \\
$\mathbf{6}$ & 17 December 1990 & 65.41 & 4.61 & 298.32 \\
$\mathbf{7}$ & 16 December 1990 & 65.68 & 4.58 & 298.17 \\
8 & 14 December 1990 & 62.07 & 4.81 & 290.89 \\
$\mathbf{9}$ & 22 August 2005 & 64.18 & 4.65 & \\
$\mathbf{1 0}$ & 12 May 1991 & 60.77 & 4.79 & \\
\hline
\end{tabular}

Focusing on the results (Table 1), it can be observed that the most significant wet spell event for the length of 1 day occurred on 23 September 1996 (in bold). This event is present in all ranking time scales, although in different positions. For the 3-day ranking, it appears in the second position. The top event is, in this case, 24 September 1996, but it is worth noting that it includes the two previous days (23 and 22 September 1996 in the calculation). Thus, it is ultimately the same event. For the 5-day ranking, the same event occurs for the 1, 2, 3, 6 and 7 positions; and for the 7-day ranking, it appears in the $6,7,9$ and 10 position. Accordingly, we focused our attention on this extreme event, 23 September 1996 , to analyse the anomalies in the accumulated precipitation field at different time scales, as well as the moisture source anomalies.

As previously mentioned, the $\mathrm{R}$ index corresponds to $\mathrm{R}=\mathrm{A} \times \mathrm{M}$, where $\mathrm{A}$ is the percentage of the area with precipitation anomalies higher than $2 \mathrm{std}$, and $\mathrm{M}$ is the mean magnitude for the area $\mathrm{A}$. For instance, the top ranked wet spell event of one day duration (23 September 1996) had a R index of $\mathrm{R}=198.65$, which corresponds to the $44.87 \%$ of area (A) of the Danube River Basin with precipitation anomalies above 2 std and 4.43 mean magnitude $(\mathrm{M})$ of the area marked with A. All magnitude values for the top 10 positions of wet spell events in duration from 1 to 7 days are shown in Table 1.

Moreover, we also need to emphasise that a specific wet spell events at a shorter time scale could not appear in the top ranking of wet spell events with longer lengths due to accumulated amount of precipitation over multi-day extreme precipitation events. That finding means that any of individual precipitation days which are included in the multi-day wet spell events are not equally represented on the highest position of the ranking at the individual daily scale.

From the results in Table 1, we can compare the domain of the affected area that shows anomalous precipitation for the wet spell events at shorter and longer time scales. The top ten events for 1-day length ranking have affected less than $50 \%$ of the Danube River Basin area. On this 1-day time scale, the top wet spell event in the ranking does not affect the largest percentage of affected area $\mathrm{A}=44.87 \%$; instead, the second ranked event affects the largest percentage of area $(\mathrm{A}=50.92 \%)$ in comparison with the top ten events in the 1-day time scale. On the other side, for wet spell events calculated for longer time scales, for instance, for the 7-day length, the first ranking event exhibited the biggest affected 
area $(\mathrm{A}=70.41 \%)$. Additionally, from Table 1 , it is possible to say that the area affected by the wet spells is higher with longer lengths of calculation. Wet spell events of shorter or longer lengths of time affect smaller or bigger percentages of the DRB area respectively. Also, from Table 1, we can notice that the most anomalous event for the 1-day ranking (23 September 1996) does not appear in the top 10 ranking wet spell events on time scale for the duration of 10 days. In this last time scale the event of 23 September 1996 has position 18 and 19. So, we can conclude that the most anomalous wet spell for the 1-day ranking was also anomalous at a 7-days period of ranking, but at the 10-days period of ranking other events appear more extreme.

\subsection{Wet Spell Event 23 September 1996}

\subsubsection{Precipitation}

As previously discussed, this paper focuses from this point forward on the 23 September 1996 wet spell event. Figure 2 shows the accumulated precipitation during this wet spell event for 1-day's duration, as well as 3-day, 5-day and 7-day (Figure 2a-d, respectively). The accumulated precipitation maximum was recorded on the western part of the Danube River Basin area with an amount of precipitation over $100 \mathrm{~mm} /$ day, reaching $150 \mathrm{~mm} /$ day in the all-time scales and reaches the southern part of the DRB for the wet spell event with duration of 7 days. Intense precipitation with values over $100 \mathrm{~mm} /$ day also occurred over the eastern part of the domain.
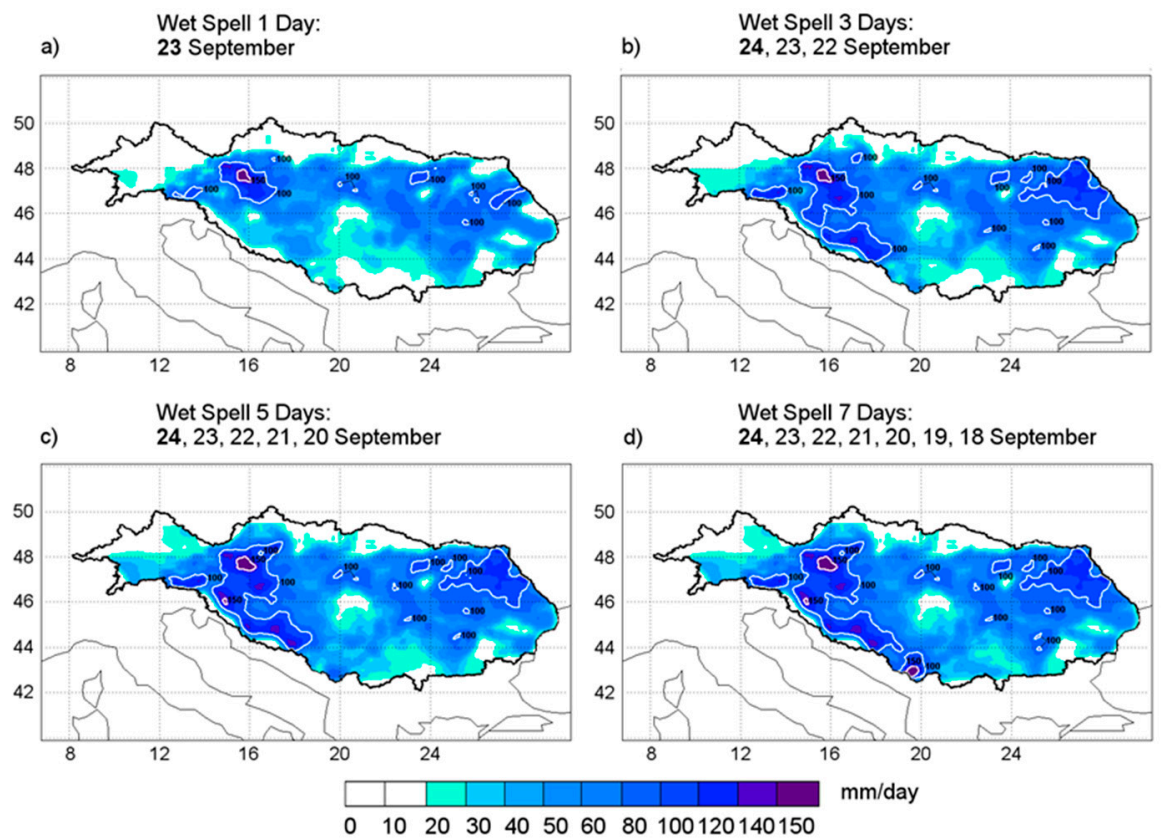

Figure 2. Accumulated precipitation (shaded, mm/day) for the 23 September 1996 wet spell event in duration of one, three, five and seven days, on the area of the DRB (Danube River Basin). White contour line corresponds to the accumulated precipitation amount of 100 and $150 \mathrm{~mm} /$ day. Daily data from CHIRPS in a $0.05^{\circ}$ degree spatial resolution in latitude and longitude.

Figure 3 shows the mean daily precipitation anomalies for the Danube River Basin area for the whole period of the CHIRPS precipitation dataset for the 23 September 1996 wet spell event at durations of one, three, five and seven days. The largest positive precipitation anomalies are stressed for the wet spell events with shorter durations, one and three days (Figure 3a,b respectively), where the magnitude of the anomalies are in a range of 30 until more than $60 \mathrm{~mm} /$ day over the main area of the Danube River Basin. Wet spell events on the longer time scales (Figure 3c,d) also showed positive values of mean daily precipitation anomalies but with considerably less value, lower than $20 \mathrm{~mm} /$ day. 

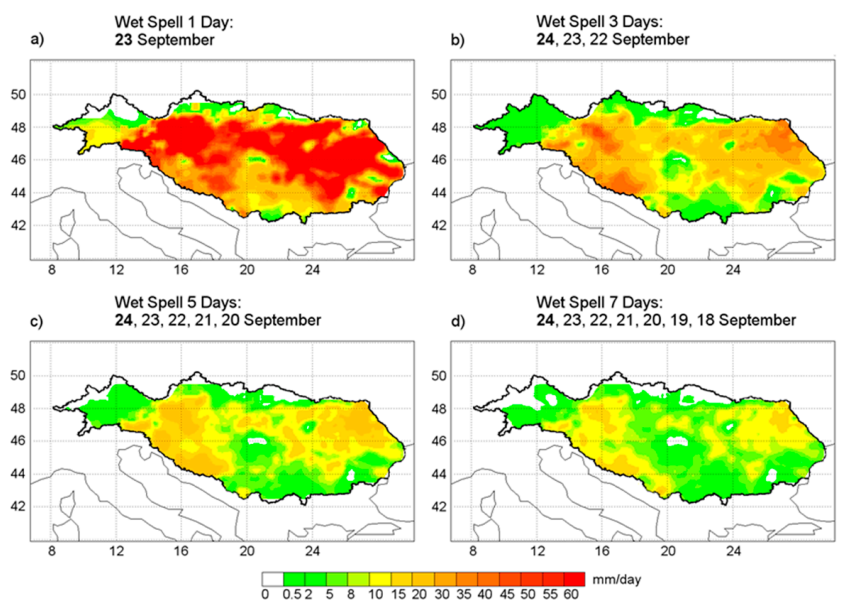

Figure 3. Mean daily values of precipitation anomalies (shaded, $\mathrm{mm} / \mathrm{day}$ ) for wet spell event of 23 September 1996 in duration of one, three, five and seven days, on the area of the DRB (Danube River Basin). Daily data from CHIRPS in a $0.05^{\circ}$ degree spatial resolution in latitude and longitude.

\subsubsection{Meteorological Configuration}

The synoptic situation for the day 23 September 1996 is shown in Figure 4. The field of daily composite mean sea level pressure (SLP) and total $850 \mathrm{hPa}$ geopotential height, and their anomalies related to the wet spell event analysed are plotted. Those panels to the left (Figure $4 a, c)$ show the climatology for 23 September 1981-2015, and the right panels (Figure 4b,d) show the anomalies. The climatological SLP and geopotential at $850 \mathrm{hPa}$ (Figure $4 \mathrm{a}, \mathrm{c}$ ) denote that over the Atlantic region an anticyclone dominates the general pattern, extending the situation over Europe and the Mediterranean region. However, the anomalies (Figure $4 \mathrm{~b}, \mathrm{~d}$ ) show an intense low-pressure system over the Italian Peninsula, the Adriatic Sea, Croatia and Slovenia. The central low peaks at $988.3 \mathrm{hPa}$ in SLP (1245.18 hPa in $850 \mathrm{hPa}$ geopotential high level). This confirms that the most anomalous wet spell event for the 1-day ranking was characterised by a cyclone over Southern Europe, crossing the area of the Danube River and leading to heavy precipitation in this region. However, one strong anticyclone is positioned over the Northern Atlantic Ocean.
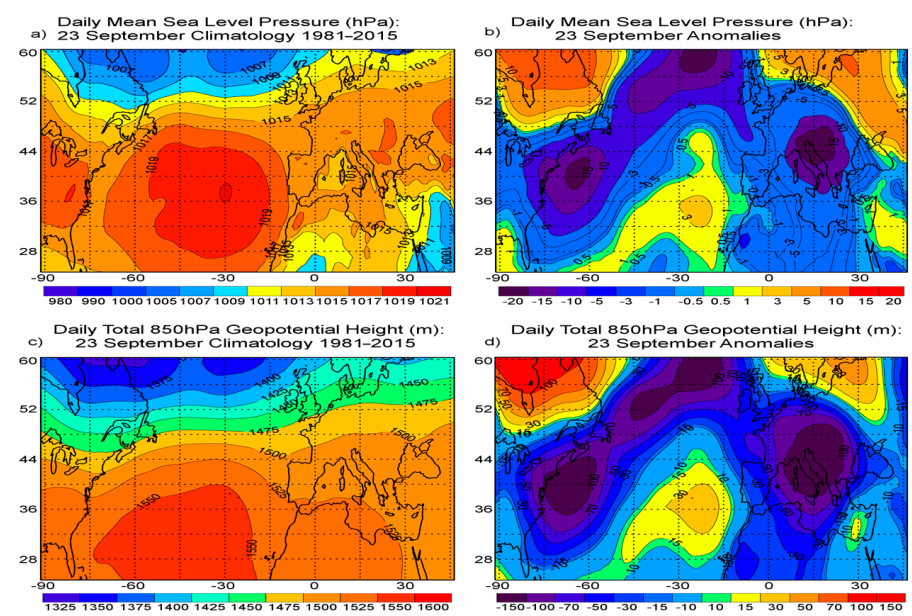

Figure 4. Top: Daily mean seal level pressure (SLP) for the day 23 September 1996 (measured in $\mathrm{hPa}$ ). Bottom: Daily total geopotential height at $850 \mathrm{hPa}$, measured for the day 23 September 1996 (in geopotential metres, gpm). Left hand column (a,c) shows the climatology for 23 September 1981-2015 and right column (b,d) the anomalies. Data obtained from ERA-Interim at $1^{\circ}$ degree in latitude and longitude. 
To show the moisture flux and vertical motion, Figure 5 shows plots for the VIMF (Vertically Integrated Moisture Flux) and its divergence for the climatology (Figure 5a) for all those 23 September dates in the period (1981-2015) and the anomaly (Figure 5b) for our studied case (23 September 1996). Between both figures, a larger difference in the distribution of the divergence-converge pattern and its values is notable. The anomalies show (Figure 5a) that over the Danube River Basin area, there is a significant region of convergence (bluish colours) that is concordant with the highest amounts of precipitation (Figures 2 and 3) experienced over the area. Conversely, Figure 5 shows two main areas of anomalous divergence (in red), one over the Mediterranean Sea and another over the Northern Atlantic Ocean, near the NW coast of the Iberian Peninsula. The convergent area over the Danube River Basin and the divergence over the Mediterranean are positioned around the low level pressure shown in Figure 4 (marked in Figure 5 with a black cross). The anomalous anticlockwise circulation is clear in the VIMF plot, showing an NW-SE direction over the area of convergence over the Mediterranean, and an S-N flow over the divergent zone in the Danube area. Over the convergence area in the Atlantic, a NW dominant flux is evident.

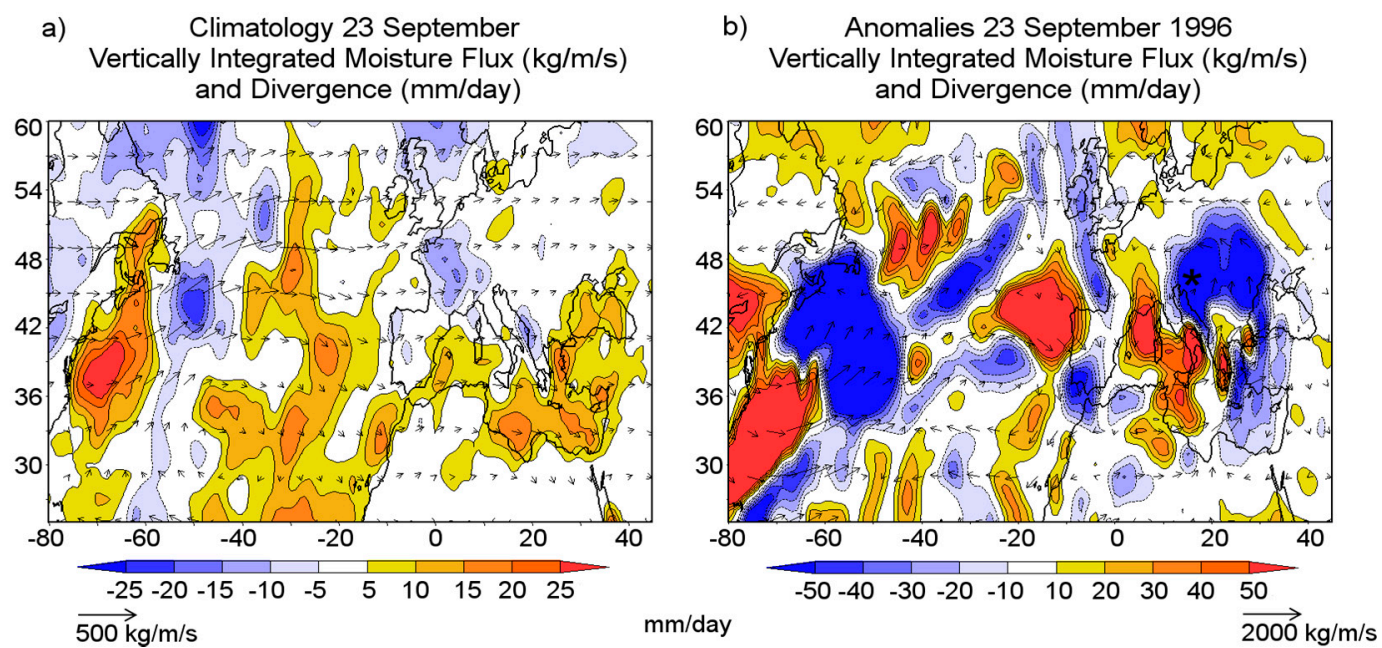

Figure 5. Left hand (a): Climatological daily mean Vertically Integrated Moisture Flux (VIMF) values for 23 September during the period 1981-2015. Right hand (b): Daily mean anomalies of VIMF values for the day 23 September 1996. Vectors measured in $\mathrm{kg} \mathrm{m}^{-1} \mathrm{~s}^{-1}$ and respective divergence shaded and measured in $\mathrm{mm}$ day $^{-1}$. The black asterisk marks the central position of the low. Data from ERA-Interim at $1^{\circ}$ degree in latitude and longitude.

\subsubsection{Anomalous Moisture Uptake during the 23 September 1996 Wet Spell Event}

Once the top-ranked wet spell event was identified for the DRB and the meteorological situation, the next step was to investigate changes in the moisture transport during the lifetime of the extreme event using a Lagrangian approach. Figure 6 shows the mean climatological sources of moisture for the 1-day, 3-day, 5-day and 7-day lengths of the wet spell. The climatology is calculated using a 35-year period (1981-2015) obtained through backward trajectories from the Danube River Basin. The backward analysis allows us to track where the particles gain humidity during their trajectories towards the area of the Danube River Basin. The colours with positive values represent areas where evaporation is greater than precipitation $(\mathrm{E}-\mathrm{P})>0$; thus, these areas are moisture sources for the DRB. On the other hand, areas where precipitation is greater than evaporation are moisture sinks $(\mathrm{E}-\mathrm{P}<0)$. In Figure 6, these areas are marked with bluish colours that represent negative values. For the 1-day length, for instance, to compute the moisture climatological field, all of the values for 23 September along the 35 years are taken into account, and for the 3-day length, the three days involved (22-24 September) for the 35 years are taken into account. The moisture source patterns (Figure 6) for the wet spell event at the different time scales exhibit similar behaviour. For all plots of 
the regions that show the major positive values of $(E-P)$, the moisture sources are the northern-central and western Mediterranean Sea, the Danube River Basin itself, and the northern and western Black Sea. This result is in concordance with a recently published paper [2] in which the sources of moisture for the DRB were analysed in depth.

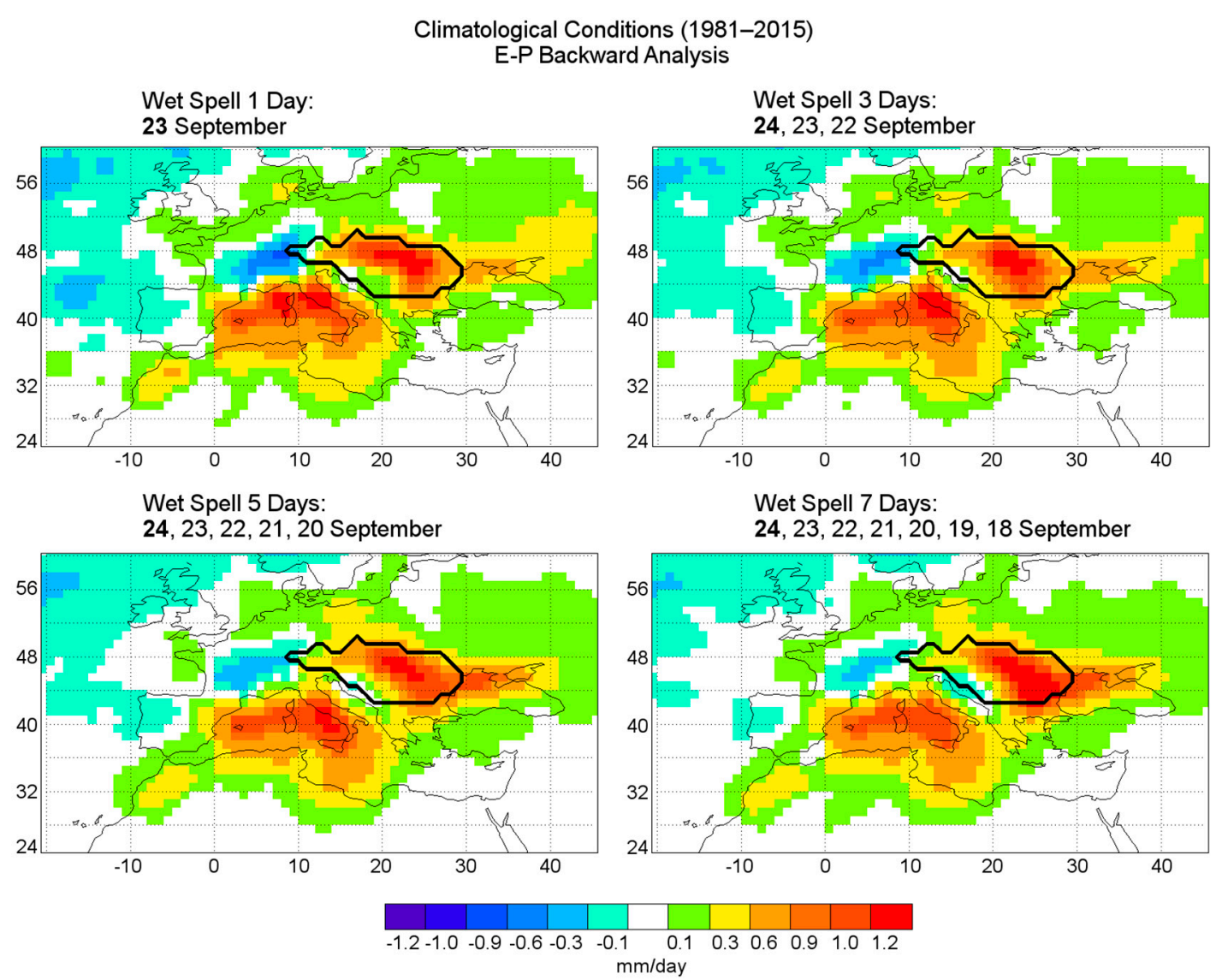

Figure 6. E - P climatological conditions from the backward analysis for 1981-2015 time period for the wet spell events on its different time scales (1,3,5 and 7 days). The black line contour corresponds to the Danube River Basin. Scale in $\mathrm{mm} /$ day.

In general, for studies about extreme events, it is critical to analyse the differences between the event studied and the climatological conditions. Therefore, the anomalies in the moisture sources field for the 23 September 1996 event on the different time scales were investigated. Figure 7 shows that during this particular wet spell event, some areas reinforced their role as sources of moisture. This phenomenon is observed for the western Black Sea and the southern and most western areas of the Mediterranean Sea. The positive anomalies values reached values higher than $2.5 \mathrm{~mm} / \mathrm{day}$ over these regions. In addition, it is important to note that a region that climatologically acted as a source can now be a sink, as is the case for the Danube River Basin and the climatological source over the northern Mediterranean Sea (Liguria Sea); and that the areas around central Italy exhibit negative anomalies. Other areas appear as effective sources of moisture, as is the case for the band over the Northern Atlantic Ocean that was not a primary climatological moisture source in the period considered (see Figure 6), but for the event analysed the anomaly pattern showed a positive signal. It is highlighted that for the shorter time scales (1 day) the anomalies are more intense than those for longer lengths (7 days). 


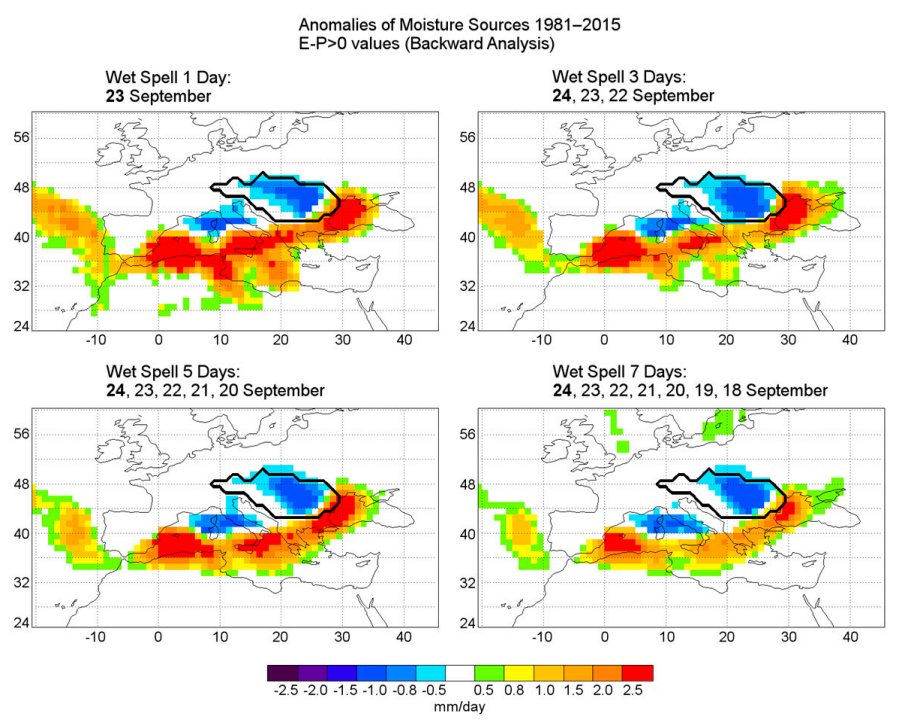

Figure 7. Anomalies of moisture sources obtained from the backward analysis ( $E-P>0$ values) for the different time scale for the 23 September 1996 wet spell. The black line contour corresponds to the Danube River Basin. Scale in $\mathrm{mm} /$ day.

The negative values in the field $\mathrm{E}-\mathrm{P}>0$ anomalies over the Danube River Basin (Figure 7 top right hand) are in concordance with the convergence in Figure 5 (right panel) and the highest amounts of precipitation.

\section{Discussion}

The configuration with an anticyclone on the left and the intense low level pressure system on the right acts as a belt of transport for the moisture over the Atlantic flowing to the Mediterranean Sea and it is available to penetrate within the storm and activates the processes for intense precipitation over the Danube River Basin (schematic process in Figure 8).

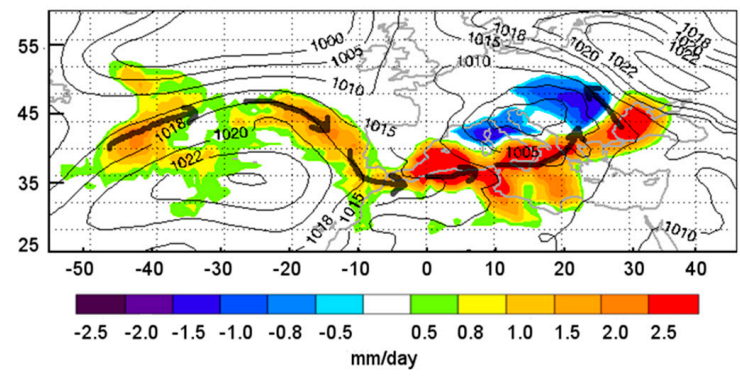

Figure 8. Anomalies of moisture sources $(E-P>0)$ obtained from the backward analysis during 10 days for the 23 September 1996 wet spell. SLP in black contours for 23 September 1996. Grey arrows indicate schematically the flow of the moisture from the Northern Atlantic Ocean to the DRB crossing the Mediterranean basin.

Despite the Mediterranean being the main moisture source for the event (about $55 \%$ of the total), the anomalous moisture from the North Atlantic Ocean deserves a little more attention. During the days prior to the low over the Danube River Basin a hurricane occurred in the North Atlantic Ocean, the Hortense hurricane (3-16 September 1996). It has been shown that the hurricane events over the Atlantic may directly impact not only western Europe (e.g., [40]), but also the Mediterranean region (e.g., [41]). Other studies [42] and references therein] state the important role of intense transports of moist air from the tropical and subtropical Atlantic in the occurrence of cold season extreme 
precipitation events in the Mediterranean region. These extreme precipitation events may originate from atmospheric processes associated with the formation of hurricanes or intense cyclones over the Atlantic Ocean. The development of these events is characterised by intense convergence of moist air from the tropics [43] that is followed by a fast intrusion of moist air into the Mediterranean region without significant mixing with the surrounding air. A significant number of these events in the Mediterranean region appear to take place during (or immediately after) Atlantic hurricanes or storms [42].

Hortense was a wet hurricane, as the National Hurricane Center reports (http://www.nhc. noaa.gov/data/tcr/AL081996_Hortense.pdf). It started as low-pressure near Africa on 30 August, it moved westward and it became in a tropical storm on 7 September near the Guadeloupe Islands. Hortense became a hurricane on 9 September over Puerto Rico, then it moved northward intensifying, and it became an extratropical low on 15 September. Figure 9 shows the synoptic configuration for SLP, wind and specific humidity at $900 \mathrm{hPa}$ using data from ERA-Interim during 14-16 September 1996, the last days during the hurricane situation and the first two days during the transition to an extratropical cyclone. It is clear that the core of the hurricane transported a higher amount of humidity to extratropical latitudes and it was available for its transport during the following 10 days, the period used for computing the $\mathrm{E}-\mathrm{P}$ anomaly.
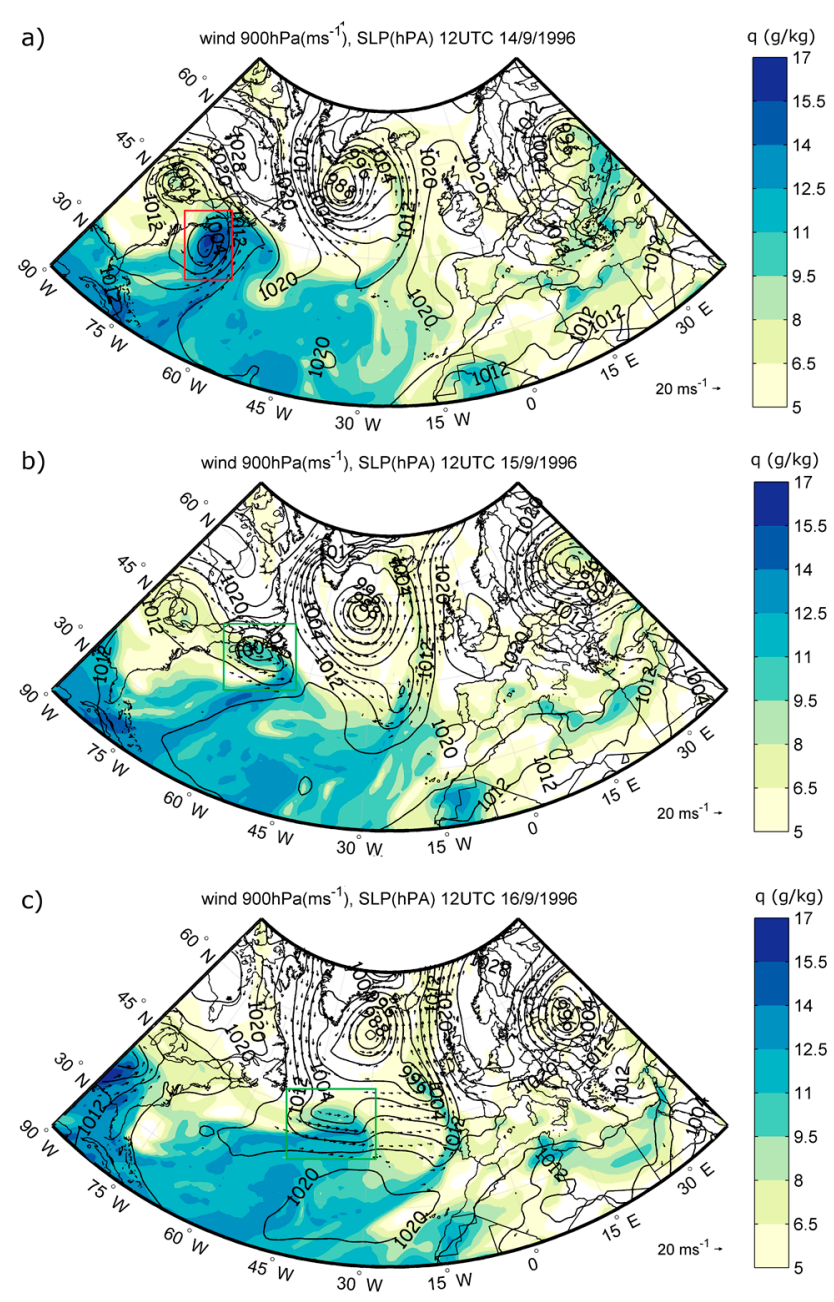

Figure 9. The wind field (vectors, $\mathrm{m} / \mathrm{s}$ ) and specific humidity (shaded, g/kg) at $900 \mathrm{hPa}$ are shown along with the Sea Level Pressure (SLP, contours, hPa) on the (a) 14 September 1996 at 12 UTC; (b) 15 September 1996 at 12 UTC and (c) 16 September 1996 at 12 UTC. In addition, Hurricane Hortense is highlighted with a red square, while it's extra-tropical transition is highlighted with a green square. Only winds speeds above $10 \mathrm{~m} / \mathrm{s}$ are shown. 
The tropical cyclones also impact downstream wave breaking, and this remote impact was demonstrated in some episodes of intense rainfall over the Mediterranean in autumn [41]. This suggests that the interaction of tropical cyclones with a midlatitude flow over the western North Atlantic may be considered a perturbation to, rather than a source of, downstream wave breaking [41].

The extratropical cyclone derived from Hortense disappeared during 19 September 1996 over the northern Iberian Peninsula (see Supplementary Material Video S1 green box), but the low over the Danube River Basin was due to a second cyclone within the wave train (Supplementary Material Video S1 blue box) that started on 18 September 1996 over the middle North Atlantic, reached the Mediterranean Sea during the next day, and it was reinforced when it was situated on the Danube region.

The extra tropical cyclone that occurs immediately after the Hortense (highlighted with the blue box on Supplementary Material Video S1) struck the Northwest Iberian Peninsula on 20 September 1996. Figure 10a shows that associated with it there was a long corridor of vertically integrated horizontal water vapour transport (IVT) with the characteristics of an Atmospheric River (AR) around $38.5^{\circ} \mathrm{N}$. ARs are relatively long, narrow regions in the atmosphere that transport most of the water vapour outside of the tropics, they contain high amounts of water vapour and they could be associated with extreme events in terms of rainfall and floods where they impact $[17,43,44]$. In fact, the ERA-Interim ARs database developed by Ramos et al. [45] for the Iberian Peninsula identifies this particular AR. Then, this fast corridor of moisture (but with lower intensity) penetrated the Mediterranean basin during the following day (Figure 10b), and on the 23 September 1996 (Figure 10d) the anomalous transport of moisture reached the Danube River Basin, associated with the low situated over our area of study. A close look at the global ARs database of Guan and Waliser [46] indicates that this particular pattern of IVT along the Mediterranean and North Africa towards the Danube is also an AR event.
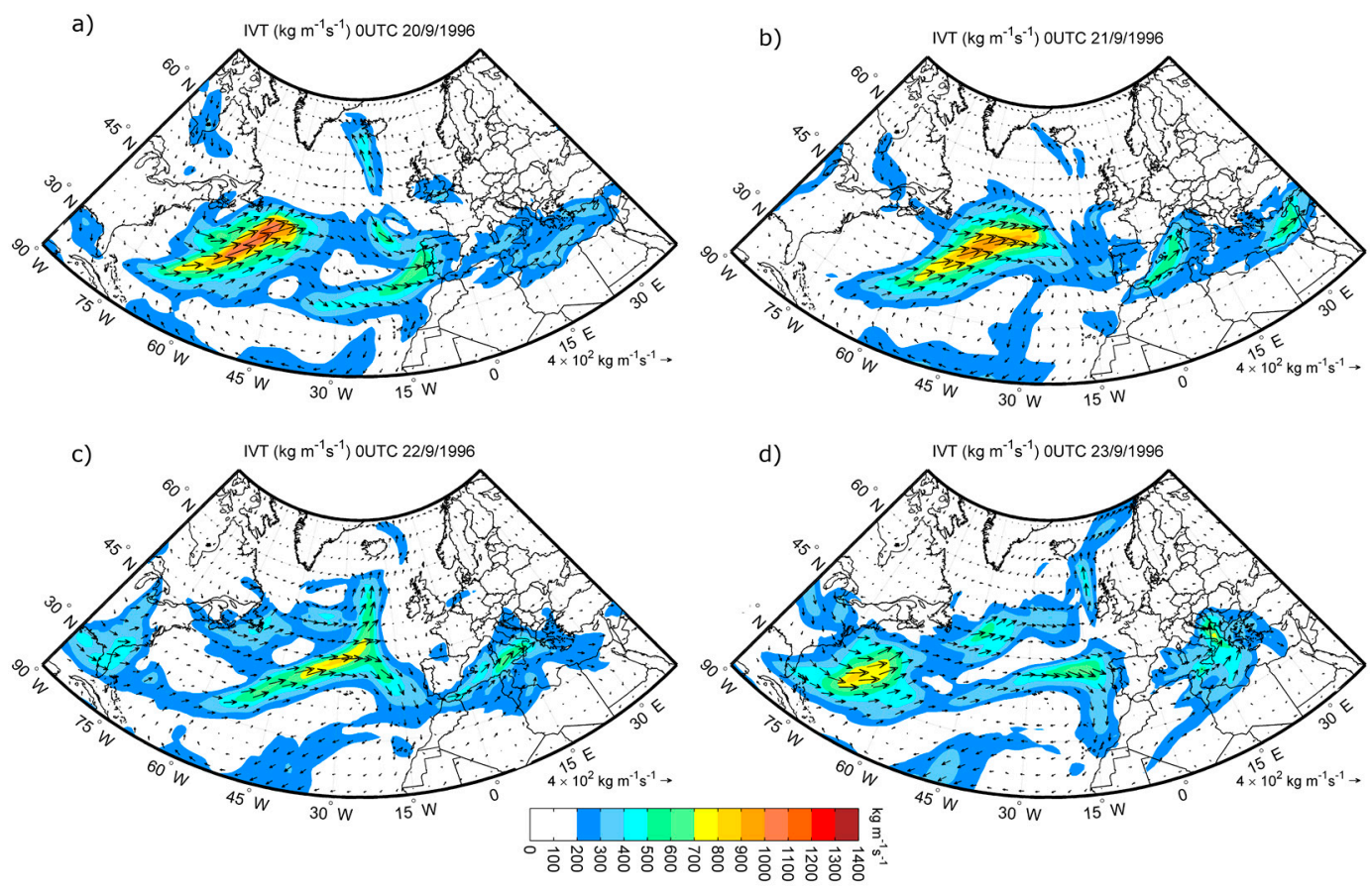

Figure 10. Vertically integrated horizontal water vapour transport (IVT) (vectors) and intensity ( $\mathrm{kg} \mathrm{m}^{-1} \mathrm{~s}^{-1}$; color shading) at (a) 20 September 1996 00UTC, (b) 21 September 1996 00UTC, (c) 22 September 1996 00UTC, and (d) 23 September 1996 00UTC. 


\section{Conclusions}

In this work, we calculated the top 10 ranking wet spell events over the Danube River Basin region using the CHIRPS daily precipitation dataset at 0.05 degrees spatial resolution and for the temporal period from 1981 until 2015, considering different time scales from 1 to 7 days using a method developed by Ramos et al. [20,21]. The most intense event detected occurred on 23 September 1996. This top ranked wet spell events is present in the first position of the ranking for the length of 1 day but also between the top 10 events on 3-, 5- and 7-day time scales. During this event, the existence of a low level surface pressure ( $988.3 \mathrm{hPa}$ in SLP) caused a situation of extreme precipitation over the $\mathrm{DRB}$, reaching values up to $100 \mathrm{~mm} /$ day with peaks of $150 \mathrm{~mm} /$ day. The magnitude of the anomalies fluctuated from 30 to $60 \mathrm{~mm} /$ day over the main area of the Danube River Basin.

The analysis of the moisture source anomalies using a Lagrangian model of particles (FLEXPART) showed that the system was fed with anomalous moisture from the western and south-central Mediterranean Sea, the western Black Sea, and the northern Atlantic Ocean. This pattern is a consequence of several synoptic conditions: the occurrence of hurricane Hortense during the days prior to the event, which lets available moisture over the North Atlantic, an anticyclone positioned over the Atlantic during at least 10 days, and a low-level pressure system that occurred immediately after this hurricane with an associated Atmospheric River that directly struck the Iberian Peninsula on 20 September and then reached the DRB through the Mediterranean Sea on 23 September 1996. The dipole in the SLP and geopotential in low tropospheric level fields due the low-level pressure and the anticyclone made this transport possible, and the occurrence of an AR was responsible for the anomalous moisture availability in the area. This anomalous moisture transport affected the Danube Basin on 23 September 1996 and produced the extreme and anomalous precipitation event.

Supplementary Materials: The following are available online at www.mdpi.com/2073-4441/9/8/615/s1.

Acknowledgments: D. Ciric is supported by European Commission under the Erasmus Mundus project Green-Tech-WB: Smart and Green Technologies for Innovative and Sustainable Societies in the Western Balkans (551984-EM-1-2014-1-ES-ERA Mundus-EMA2). A.M. Ramos was supported through a postdoctoral grant (SFRH/BPD/84328/2012) from the Fundação para a Ciência e a Tecnologia (FCT, Portuguese Science Foundation). We also thank the IMDROFLOOD project financed by the Water Works 2014 co-funded call of the European Commission. We thank Bin Guan for providing the AR database and both anonymous referees for their effort and comments that have improved this paper.

Author Contributions: D. Ciric, R. Nieto, and L. Gimeno conceived and designed the experiments; D. Ciric and A.M. Ramos performed the experiments and D. Ciric, R. Nieto, A.M. Ramos, and L. Gimeno analysed the data; D. Ciric, R. Nieto, A. Drumond and A.M. Ramos wrote the paper.

Conflicts of Interest: The authors declare no conflict of interest. The founding sponsors had no role in the design of the study; in the collection, analyses, or interpretation of data; in the writing of the manuscript; and in the decision to publish the results.

\section{References}

1. Lehner, B.; Döll, P.; Alcamo, J.; Henrichs, T.; Kaspar, F. Estimating the Impact of Global Change on Flood and Drought Risks in Europe: A Continental, Integrated Analysis. Chlimatic. Chang. 2006, 75, 273-299. [CrossRef]

2. Ciric, D.; Stojanovic, M.; Drumond, A.; Nieto, R.; Gimeno, L. Tracking the Origin of Moisture over the Danube River Basin Using a Lagrangian Approach. Atmosphere 2016, 7, 162. [CrossRef]

3. Stancik, A.; Jovanovic, S. Hidrology of the River Danube; Priroda: Bratislava, Slovakia, 1988; p. 272.

4. Brilly, M. Hydrological Processes of the Danube River Basin: Perspective from the Danubian Countries; Springer Science \& Business Media: Ljubljana, Slovenia, 2010; Volume 1, p. 436. [CrossRef]

5. Zolina, O. Multidecadal trends in the duration of wet spells and associated intensity of precipitation as revealed by a very dense observational German network. Environ. Res. Lett. 2014, 9, 025003. [CrossRef]

6. Kaspar, M.; Müller, M. Selection of historic heavy large-scale rainfall events in the Czech Republic. Nat. Hazards Earth Syst. Sci. 2008, 8, 1359-2008. [CrossRef] 
7. Babić, M.; Babić-Mladenović, M.; Danko, B.; Pavel, B.; Razvan, B.; Lenka, C. Flood Risk Management Plan for the Danube River Basin District; International Commission for the Protection of the Danube River: Vienna, Austria, 2015.

8. Blöschl, G.; Nester, T.; Komma, J.; Parajka, J.; Perdigão, R.A.P. The June 2013 flood in the Upper Danube Basin, and comparisons with the 2002, 1954 and 1899 floods. Hydrol. Earth Syst. Sci. 2013, 17, 5197-5212. [CrossRef]

9. Stadtherr, L.; Coumou, D.; Petoukhov, V.; Petri, S.; Rahmstorf, S. Record Balkan floods of 2014 linked to planetary wave resonance. Sci. Adv. 2016, 2, e1501428. [CrossRef] [PubMed]

10. EASAC. Trends in Extreme Weather Events in Europe: Implications for National and European Union Adaptation Strategies; EASAC Policy Report 22; European Academies Science Advisory Council: Halle, Germany, 2013; Available online: www.easac.eu (accessed on 24 April 2017).

11. Martín, M.L.; Santos-Muñoz, D.; Morata, A.; Luna, M.Y.; Valero, F. An objectively selected case study of a heavy rain event in the Mediterranean Basin: A diagnosis using numerical simulation. Atmos. Res. 2006, 81, 187-205. [CrossRef]

12. Jansa, A.; Genoves, A. Western Mediterranean cyclones and heavy rain. Part 1: Numerical experiment concerning the Piedmont flood case. Meteorol. Appl. 2000, 7, 323-333. [CrossRef]

13. Liberato, M.L.R.; Pinto, J.G.; Trigo, I.F.; Trigo, R.M. Klaus, an exceptional winter storm over Northern Iberia and Southern France-A comparison between storm diagnostics. Weather 2011, 66, 330-334. [CrossRef]

14. Duan, Z.; Bastiaanssen, W.G.M. First results from Version 7 TRMM 3B43 precipitation product in combination with a new downscaling-Calibration procedure. Remote Sens. Environ. 2013, 131, 1-13. [CrossRef]

15. Ratan, R.; Venugopal, V. Wet and dry spell characteristics of global tropical rainfall. Water Resour. Res. 2013, 49, 3830-3841. [CrossRef]

16. Singh, D.; Tsiang, M.; Rajaratnam, B.; Diffenbaugh, N.S. Observed changes in extreme wet and dry spells during the South Asian summer monsoon season. Nat. Clim. Chang. 2014, 4, 456-461. [CrossRef]

17. Gimeno, L.; Dominguez, F.; Nieto, R.; Trigo, R.M.; Drumond, A.; Reason, C.; Taschetto, A.S.; Ramos, A.M.; Kumar, R.; Marengo, J. Major Mechanisms of Atmospheric Moisture Transport and Their Role in Extreme Precipitation Events. Annu. Rev. Environ. Res. 2016, 41, 117-141. [CrossRef]

18. Gimeno, L.; Drumond, A.; Nieto, R.; Trigo, R.M.; Stohl, A. On the origin of continental precipitation. Geophys. Res. Lett. 2010, 3, L13804. [CrossRef]

19. Gimeno, L.; Stohl, A.; Trigo, R.M.; Domínguez, F.; Yoshimura, K.; Yu, L.; Drumond, A.; Durán-Quesada, A.M.; Nieto, R. Oceanic and Terrestrial Sources of Continental Precipitation. Rev. Geophys. 2012, 50, RG4003. [CrossRef]

20. Ramos, A.M.; Trigo, R.M.; Liberato, M.L.R. A ranking of high-resolution daily precipitation extreme events for the Iberian Peninsula. Atmos. Sci. Lett. 2014, 15, 328-334. [CrossRef]

21. Ramos, A.M.; Trigo, R.M.; Liberato, M.L.R. Ranking of multi-day extreme precipitation events over the Iberian Peninsula. Int. J. Clim. 2017, 37, 607-620. [CrossRef]

22. Funk, C.; Peterson, P.; Landsfeld, M.; Pedreros, D.; Verdin, J.; Shukla, S.; Husak, G.; Rowland, J.; Harrison, L.; Hoell, A.; et al. The climate hazards infrared precipitation with stations-A new environmental record for monitoring extremes. Sci. Data 2015, 2, 150066. [CrossRef] [PubMed]

23. Paredes-Trejoa, F.J.; Barbosa, H.A.; Lakshmi Kumar, T.V. Validating CHIRPS-based satellite precipitation estimates in Northeast Brazil. J. Arid Environ. 2017, 139, 26-40. [CrossRef]

24. Duan, Z.; Liu, J.; Tuo, Y.; Chiogna, G.; Disse, M. Evaluation of eight high spatial resolution gridded precipitation products in Adige Basin (Italy) at multiple temporal and spatial scales. Sci. Total Environ. 2016, 573, 1536-1553. [CrossRef] [PubMed]

25. Tuo, Y.; Duan, Z.; Disse, M.; Chiogna, G. Evaluation of precipitation input for SWAT modeling in Alpine catchment: A case study in the Adige river basin (Italy). Sci. Total Environ. 2016, 573, 66-82. [CrossRef] [PubMed]

26. Katsanos, D.; Retalis, A.; Tymvios, F.; Michaelides, S. Analysis of precipitation extremes based on satellite (CHIRPS) and in situ dataset over Cyprus. Nat. Hazards 2016, 83, 53-63. [CrossRef]

27. Khandu; Awange, J.L.; Forootan, E. An evaluation of high-resolution gridded precipitation products over Bhutan (1998-2012). Int. J. Climatol. 2015, 36, 1067-1087. [CrossRef]

28. Hart, R.E.; Grumm, R.H. Using normalised climatological anomalies to rank synoptic-scale events objectively. Mon. Weather Rev. 2001, 129, 2426-2442. [CrossRef] 
29. Dee, D.P.; Uppala, S.M.; Simmons, A.J.; Berrisford, P.; Poli, P.; Kobayashi, S.; Andrae, U.; Balmaseda, M.A.; Balsamo, G.; Bauer, P.; et al. The ERA-Interim reanalysis: Configuration and performance of the data assimilation system. Q. J. R. Meteorol. Soc. 2011, 137, 553-597. [CrossRef]

30. Stohl, A.; James, P. A Lagrangian analysis of the atmospheric branch of the global water cycle. Part I: Method description, validation, and demonstration for the August 2002 flooding in central Europe. J. Hydrometeorol. 2004, 5, 656-678. [CrossRef]

31. Stohl, A.; James, P. A Lagrangian analysis of the atmospheric branch of the global water cycle: Part II: Moisture transports between Earth's ocean basins and river catchments. J. Hydrometeorol. 2005, 6, 961-984. [CrossRef]

32. Numaguti, A. Origin and recycling processes of precipitating water over the Eurasian continent: Experiments using an atmospheric general circulation model. J. Geophys. Res. 1999, 104, 1957-1972. [CrossRef]

33. Drumond, A.; Nieto, R.; Hernandez, E.; Gimeno, L. A Lagrangian analysis of the variation in moisture sources related to drier and wetter conditions in regions around the Mediterranean Basin. Nat. Hazards Earth Syst. Sci. 2011, 11, 2307-2320. [CrossRef]

34. Duran-Quesada, A.M.; Gimeno, L.; Amador, J.A.; Nieto, R. Moisture sources for Central America: Identification of moisture sources using a Lagrangian analysis technique. J. Geophys. Res. 2010, 115, D05103. [CrossRef]

35. Gimeno, L.; Nieto, R.; Trigo, R.M.; Vicente-Serrano, S.M.; Lopez-Moreno, J.I. Where Does the Iberian Peninsula Moisture Come from? An Answer Based on a Lagrangian Approach. J. Hydrometeorol. 2010, 11, 421-436. [CrossRef]

36. Nieto, R.; Gimeno, L.; Gallego, D.; Trigo, R.M. Contributions to the moisture budget of airmasses over Iceland. Meteorol. Z. 2007, 16, 037-044. [CrossRef]

37. Sodemann, H.; Schwierz, C.; Wernli, H. Interannual variability of Greenland winter precipitation sources: Lagrangian moisture diagnostic and North Atlantic Oscillation influence. J Geophys. Res. 2008, 113, D03107. [CrossRef]

38. Drumond, A.; Nieto, R.; Gimeno, L. Sources of moisture for China and their variations during drier and wetter conditions in 2000-2004: A Lagrangian approach. Clim. Res. 2011, 50, 215-225. [CrossRef]

39. Sorí, R.; Nieto, R.; Drumond, R.; Gimeno, L. The Niger River Basin Moisture Sources: A Lagrangian Analysis. Atmosphere 2017, 8, 38. [CrossRef]

40. Hickey, K.R.; Connolly-Johnston, C. The Impact of Hurricane Debbie (1961) and Hurricane Charley (1986) on Ireland. In Advances in Hurricane Research-Modelling, Meteorology, Preparedness and Impacts; Hickey, K., Ed.; InTech: Rijeka, Croatia, 2012; Chapter 9; Volume 1, pp. 183-198. [CrossRef]

41. Pantillon, F.; Chaboureau, J.P.; Richard, E. Remote impact of North Atlantic hurricanes on the Mediterranean during episodes of intense rainfall in autumn 2012. Q. J. R. Meteorol. Soc. 2015, 141, 967-978. [CrossRef]

42. Krichak, S.O.; Feldstein, S.B.; Alpert, P.; Gualdi, S.; Scoccimarro, E.; Yano, J.I. Discussing the role of tropical and subtropical moisture sources in cold season extreme precipitation events in the Mediterranean region from a climate change perspective. Nat. Hazards Earth Syst. Sci. 2016, 16, 269-285. [CrossRef]

43. Ralph, F.M.; Dettinger, M.D. Storms, floods, and the science of atmospheric rivers. EOS Trans. Am. Geophys. Union 2011, 92, 265-272. [CrossRef]

44. Gimeno, L.; Nieto, R.; Vázquez, M.; Lavers, D.A. Atmospheric rivers: A mini-review. Front. Earth Sci. 2014, 2, 2. [CrossRef]

45. Ramos, A.M.; Trigo, R.M.; Liberato, M.L.R.; Tome, R. Daily precipitation extreme events in the Iberian Peninsula and its association with Atmospheric Rivers. J. Hydrometeorol. 2015, 16, 579-597. [CrossRef]

46. Guan, B.; Waliser, D.E. Detection of atmospheric rivers: Evaluation and application of an algorithm for global studies. J. Geophys. Res. Atmos. 2015, 120, 12514-12535. [CrossRef]

(C) 2017 by the authors. Licensee MDPI, Basel, Switzerland. This article is an open access article distributed under the terms and conditions of the Creative Commons Attribution (CC BY) license (http://creativecommons.org/licenses/by/4.0/). 